\title{
Effects of the length and timing of nighttime naps on task performance and physiological function
}

\author{
Hidemaro Takeyamaa, Shun Matsumotob, Kensaburo Murataa, Takeshi Ebara ${ }^{a}$, Tomohide \\ Kubo ${ }^{a}$, Norihide Tachi ${ }^{\mathrm{a}}$ and Toru Itani ${ }^{\mathrm{a}}$
}

a Health Sciences of Life, Work and Environment. Department of Environmental Health Science and Health Promotion. Nagoya City University Graduate School of Medical Sciences. Nagoya, Japan.

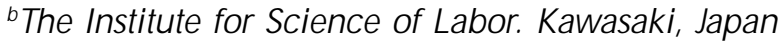

\section{Keywords}

Night work. Shift work. Sleep, physiology. Students. Questionnaires.

\section{Descritores}

Trabalho noturno. Trabalho em turnos. Sono, fisiologia. Estudantes. Questionários.

\begin{abstract}
Objective

To examine the effects of the length and timing of nighttime naps on performance and physiological functions, an experimental study was carried out under simulated night shift schedules.

Methods

Six students were recruited for this study that was composed of 5 experiments. Each experiment involved 3 consecutive days with one night shift (22:00-8:00) followed by daytime sleep and night sleep. The experiments had 5 conditions in which the length and timing of naps were manipulated: 0:00-1:00 (E60), 0:00-2:00 (E120), 4:00-5:00 (L60), 4:00-6:00 (L120), and no nap (No-nap). During the night shifts, participants underwent performance tests. A questionnaire on subjective fatigue and a critical flicker fusion frequency test were administered after the performance tests. Heart rate variability and rectal temperature were recorded continuously during the experiments. Polysomnography was also recorded during the nap.

\section{Results}

Sleep latency was shorter and sleep efficiency was higher in the nap in L60 and L120 than that in E60 and E120. Slow wave sleep in the naps in E120 and L120 was longer than that in E60 and L60. The mean reaction time in L60 became longer after the nap, and faster in E60 and E120. Earlier naps serve to counteract the decrement in performance and physiological functions during night shifts. Performance was somewhat improved by taking a 2-hour nap later in the shift, but deteriorated after a one-hour nap.

Conclusions

Naps in the latter half of the night shift were superior to earlier naps in terms of sleep quality. However performance declined after a 1-hour nap taken later in the night shift due to sleep inertia. This study suggests that appropriate timing of a short nap must be carefully considered, such as a 60-min nap during the night shift.
\end{abstract}

\section{Resumo}

Objetivo

Para investigar os efeitos da duração e horário de cochilos noturnos sobre o desempenho e as funções fisiológicas foi realizado um estudo experimental por meio do trabalho noturno simulado.

Presented at the XVI International Symposium on Night and Shiftwork, N ovember 2003. Santos, SP, Brazil. This work was supported in part by a G rant-in-Aid for Scientific Research (B) 14370142 from the Ministry of Education, Culture, Sports, Science and Technology, Japan. Received on 15/3/2004. Approved on 27/9/2004
Correspondence to:

Health Sciences of Life, Work and Environment Nagoya City University Graduate School of Medical Sciences

Kawasumi 1, Mizuho-ku, Nagoya 467-8601, Japan E-mail: hidemaro@med.nagoya-cu.ac.jp 


\begin{abstract}
Métodos
Seis estudantes foram recrutados para o estudo que consistiu de cinco experimentos. Cada experimento consistia de três dias consecutivos com um turno noturno (22:008:00h) seguido por um período de sono diurno e noturno. Os experimentos compreendiam cinco condições em que a duração e o horário dos cochilos eram manipulados: 0:00-1:00 (E60), 0:00-2:00 (E120), 4:00-5:00 (L60), 4:00-6:00 (L120) e sem cochilo (N-nap). Durante os turnos noturnos, os participantes foram submetidos a testes de desempenho. Um questionário sobre cansaço subjetivo e um teste de freqüência crítica de luz foram aplicados depois dos testes de desempenho. A variabilidade da frequiência cardíaca e a temperatura retal foram registrados continuamente durante os experimentos. Polissonografia também foi realizada durante o cochilo.

Resultados

A latência de sono foi menor e a eficiência do sono maior no cochilo em L60 e L120 que em E60 e E120. O sono de ondas lentas nos cochilos em E120 e L120 foi mais longo que em E60 e L60. O tempo médio de reação em L60 ficou mais longo depois do cochilo e mais rápido em E60 e E120. Os cochilos em horário mais cedo serviram para neutralizar a queda no desempenho e funções fisiológicas durante o turno noturno. Houve uma ligeira melhora do desempenho ao se tirar um cochilo de duas horas num horário mais tarde durante o turno, mas houve piora depois de um cochilo de uma hora.

Conclusões

Os cochilos na última metade do turno noturno foram melhores em termos de qualidade de sono do que os cochilos em um horário mais cedo. $O$ desempenho, no entanto, piorou depois de um cochilo de uma hora em um horário mais tarde durante o turno por causa da inércia do sono. O estudo indica que o horário adequado de um cochilo curto deve ser cuidadosamente considerado, tal como um cochilo de 60 minutos durante o turno noturno.
\end{abstract}

\section{INTRODUCTION}

Shift workers tend to suffer from a chronic lack of sleep or cumulative fatigue from being compelled to follow a wake-sleep cycle not conforming to their innate biological rhythms. ${ }^{6}$ Sleepiness and fatigue among shift workers are known as potential risks for occupational safety and health in many industries. ${ }^{1,4}$ Taking a nap during the night shift has been suggested as an effective way to prevent fatigue or other complaints related to shiftwork. ${ }^{8}$ On the other hand, nighttime naps have a transient negative effect on performance immediately after awakening. This effect is known as "sleep inertia".

Previous studies have reported that the severity of sleep inertia depends on the timing of the nap taken and the sleep stage just before awakening. ${ }^{79}$ Therefore, it is necessary to consider the effect of nap length and timing on performance and alertness. It is suggested that an approximately two-hour nap is an appropriate length, because the first cycle of nocturnal sleep in adults usually lasts approximately two hours including the duration of both Slow Wave Sleep and REM sleep. However, some studies indicate a similar effect on alertness after less than a 2-hour nap compared with a 2-hour nap. ${ }^{11,14}$
Regarding the timing of the nap, Gillberg ${ }^{5}$ indicated that performance in the early morning after a 1-hour nap in the later half of the night shift was superior to that during the first half of the night shift. Sallinen et al ${ }^{15}$ reported that a nap shorter than 1-hour starting at 1:00 or 3:50 improved alertness in the early morning. However, there are few studies that focus on the timing and length of nighttime naps. In the present study, the effects of the length and timing of nighttime naps on changes in task performance and physiological functions were investigated by an experimental study carried out under simulated night shift schedules.

\section{METHODS}

\section{Participants and design}

Six students voluntarily participated in this study. All participants were healthy males, aged 19-22 yrs, non-smokers and not taking medications continuously. Participants were given a detailed description of the study, and their informed consent was obtained in writing. The study was composed of 5 experiments, each lasting 3 consecutive days with one night shift (22:00-8:00), followed by day sleep (11:30-17:00) and night sleep (0:00-7:00). The experiments had 5 different conditions in which the length and timing 
of naps were manipulated: 0:00-1:00 (E60), 0:00-2:00 (E120), 4:00-5:00 (L60), 4:00-6:00 (L120) and no nap (No-nap). All participants underwent the five experiments in a counterbalanced order. In order to minimize carry-over effects, there were at least five days between the experiments. The participants were instructed to do their usual daily activities and sleep between the experiments. Their sleep and awake between the experiments were measured by an actigraph. None of the participants appeared chronic or acute sleep deprivation before the experiment. On the day before the beginning of the first series of experiments the participants visited the laboratory to practice the performance tests and also slept overnight in the laboratory for adaptation to experimental environment.

During the night shifts, the participants were requested to do a set of task and performance tests every hour except when they were taking a nap. The task consisted of typing documents into a computer for 30 minutes. Performance tests were composed of a choice reaction time test (CRT), a logical reasoning test (LRT), a vigilance test (VT), and a critical flicker fusion frequency test $(\mathrm{CFF})$. After the performance tests, the participants filled out a questionnaire on subjective fatigue. It took about 20 minutes to finish the 4 performance tests and the questionnaire. Therefore, the participants were able to take a break of at least 5 minutes before moving to the next set.

The participants were served two biscuits and 60 $\mathrm{ml}$ of mineral water every break time during the night shifts. In this study, the total number of task and performance tests differed among nap conditions. The number of the task and the performance tests during night shift was 10 for N-nap, 8 for E60 and L60, and 7 for E120 and L120. Electroencephalography (EEG), electrooculography (EOG), and electromyography (EMG) were recorded during adaptation to night sleep, nighttime naps, daytime sleep and night sleep. During all experiments, heart rate variability was continuously recorded except while taking a bath.

\section{Measurements}

A computerized test battery, including a CRT, a VT, and a LRT, was used. In the CRT, the participants were asked to press keys as quickly as possible with a finger of the dominant hand when a figure appeared randomly in the center of the displays. The test procedure for VT was similar to CRT, but the intervals for presenting the numbers on the display were arranged randomly between 1 and $10 \mathrm{sec}$. The LRT was performed as described by Baddeley. "AB", or "BA", were randomly shown, followed below by " $\mathrm{A}$ is ahead of B," "A is not preceded by B," " $\mathrm{B}$ follows A," and so on. Participants were requested to answer true or false by pressing the appropriate key as quickly as possible. Critical flicker fusion frequencies were examined by recognizing a blinking light using the Roken Digital Flicker (model RDF-1; Shibata Co., Ltd., Tokyo, Japan). The participants gazed at a red light placed in the middle of a slightly illuminated screen. The red light was presented automatically with flicker frequencies ranging from $60 \mathrm{~Hz}$ to $25 \mathrm{~Hz}$ in descending order. Participants were requested to press a button when they perceived flickering. The measurements were performed five times.

EEG, EOG, and EMG were recorded with Poltmate AP1124 (TEAC Instruments Co., Ltd, Japan). Sleep stages were analyzed according to Rechtschffen and Kales. ${ }^{13}$ The EEG and EOG were recorded from the $\mathrm{C} 4$ A1, C3-A2, E1-A1, and E2-A1 using silver-silver chloride electrodes. The EMG was recorded with disposable electrodes. The questionnaire consisted of 25 questions with regard to subjective fatigue feeling established by the Research Group for Occupational Fatigue of Japan Society for Occupational Health. ${ }^{15}$ Heart rate variability was recorded with a Holter type ECG recorder (Active Tracer AC301, GMS Inc., Tokyo, Japan) during all experiments. The data were entered in a computer after measurement. Then the frequency analysis of R-R intervals by the Memcalc system (Suwa Trust Co., Ltd., Japan), and high frequency power (HF; 0.15$0.4 \mathrm{~Hz}$ ) and low frequency power (LF; 0.04-0.15 Hz) were calculated. The component of high frequency power and LF/HF were taken as the index of parasympathetic and sympathetic nerve activity, respectively. ${ }^{10}$ Mean values of power components were calculated every hour during the night shift. The results were the values in relation to the mean values during the entire night shift.

\section{Data analysis}

Each item on the questionnaire was scored on a 1 to 5 points scale. The average rates of complaints regarding 5 factors (feeling of drowsiness, instability, uneasiness, local pain or dullness, and eyestrain) were calculated.

The sleep physiology data were analyzed by factorial two-way ANOVA by "timing of naps" and "length of naps" as factors. Fatigue, CFF and performance data from all nap conditions $(22: 30,23: 30,2: 30$, $3: 30,6: 30,7: 30$ ) were analyzed by two-way, repeated measures ANOVA with "time" and "nap condition" as factors. Our main interest was in the interaction effect. However, no significant interactions were observed. Therefore, the results for fatigue, CFF and performance tests during the night shift were indi- 
Table - Sleep length and stages during 4 naps.

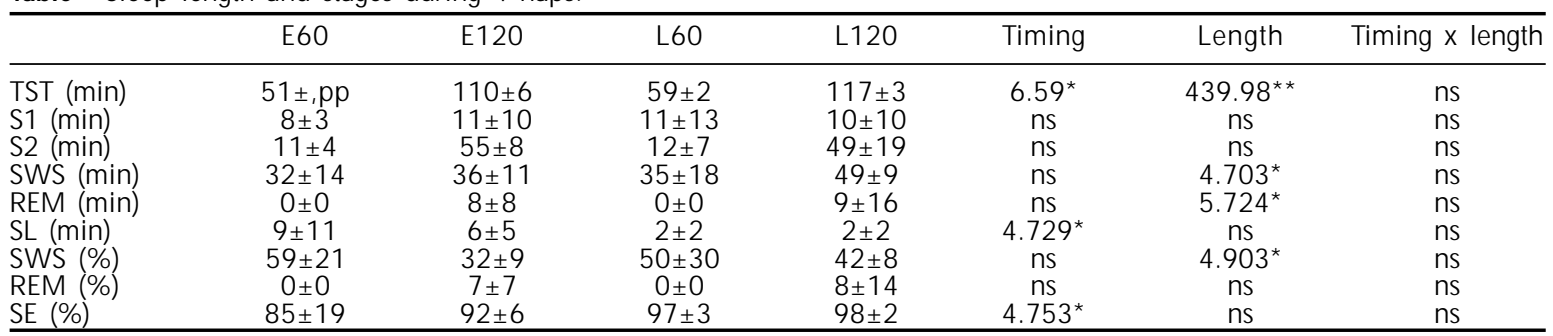

TST: Total sleep time; S1: stage 1; S2: stage 2; SWS: Slow wave sleep; REM: Rapid eye movement; SL: Sleep latency; SWS: percent of SWS; REM : percent of REM (proportion of REM sleep of TST); SE: percent of sleep efficiency (proportion of TST of time in bed)

$* P<0.05 ; * * P<0.01$

cated as relative changes in relation to the values just before beginning of night shift (21:30). Comparisons between the 5 nap conditions at the same measurement points were performed using one-way ANOVA. Post-hoc analysis was done using Scheffe's method. Statistical analyses were performed using SPSS version 10.0.

\section{RESU LTS}

Sleep latency for the nap in L60 and L120 was significantly shorter than for the nap in E60 and E120 (Table). Total sleep time was significantly longer and sleep efficiency was also higher in the nap in L60 and L120 than in the nap in E60 and E120. On the other hand, Slow Wave Sleep and its percent of total sleep in the nap in E120 and L120 was significantly longer than in the nap in E60 and L60. There were no significant interactions between time and length of naps on any of the sleep parameters. There was no significant difference in the HF component of heart rate variability (an index of parasympathetic nerve activity) between the naps taken in the second half of the night shift and those in the first half of the night shift. Mean reaction times of VT and RT in the N-nap condition deteriorated as the night work progressed.

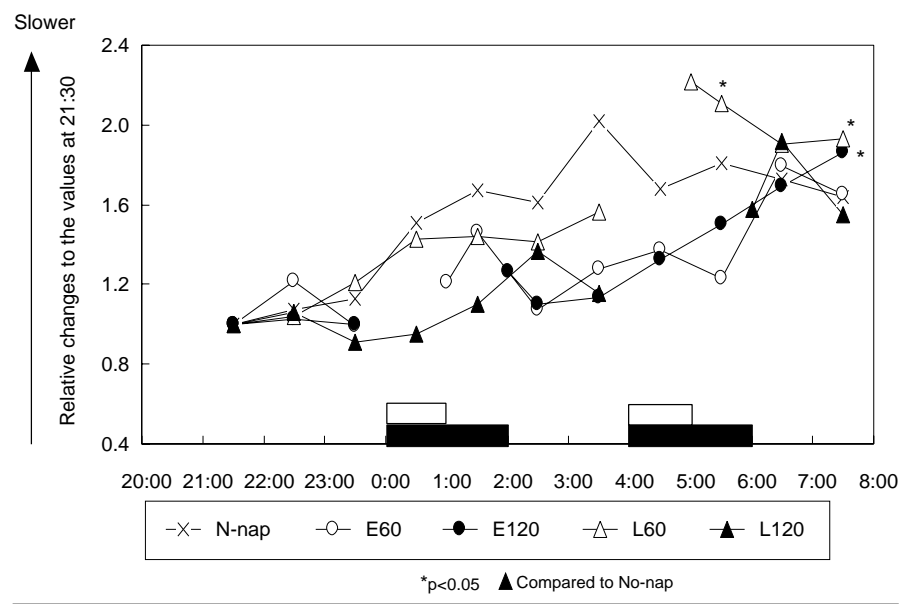

Figure 1 - Changes in mean reaction time of vigilance test during night shift.
Although the mean reaction times in VT and RT tended to be faster after the nap in E60 and E120 compared to N-nap condition, there was no significant deference (Figure 1 and 2). However, significant delay in mean reaction time at 8:00 was observed in the E120 condition. There were no positive effects of L60 and L120 on mean reaction times after the naps. On the contrary, in L60 significant delays in mean reaction time were observed after nap compared to $\mathrm{N}$ nap. The CFF values tended to improve after the nap in E60 and E120 compared with No-nap (Figure 3). The CFF values after the nap in L60 had an apparent tendency to deteriorate but the differences were not significant. Drowsiness score increased as night work progressed in the No-nap condition (Figure 4). In the four experimental conditions, drowsiness tended appeared to be suppressed after the nap compared with the No-nap but there were no significant differences. The scores for local pain or dullness in L60 and L120 tended to decrease after the nap. Feelings of instability, uneasiness, and eyestrain showed fewer differences between nap conditions.

\section{DISCUSSION}

The sleep efficiency of 120- and 60-min naps in the latter half of the night shift was higher than in the earlier two naps, and slow wave sleep in the two 120-min naps was longer than in the two 60-min naps. Therefore, a 120min nap in the latter half of the night shift was superior to other nap conditions in terms of sleep quality. These findings were consistent with previous studies indicating the superiority of naps taken near the circadian nadir. ${ }^{5,14}$ The data on higher parasympathetic nerve activity during the 120-min and 60min naps in the latter half of the night shift compared with the 120-min and 60-min naps in the former half is consistent with the sleep quality data.

Task performance after 120-min and 60- 


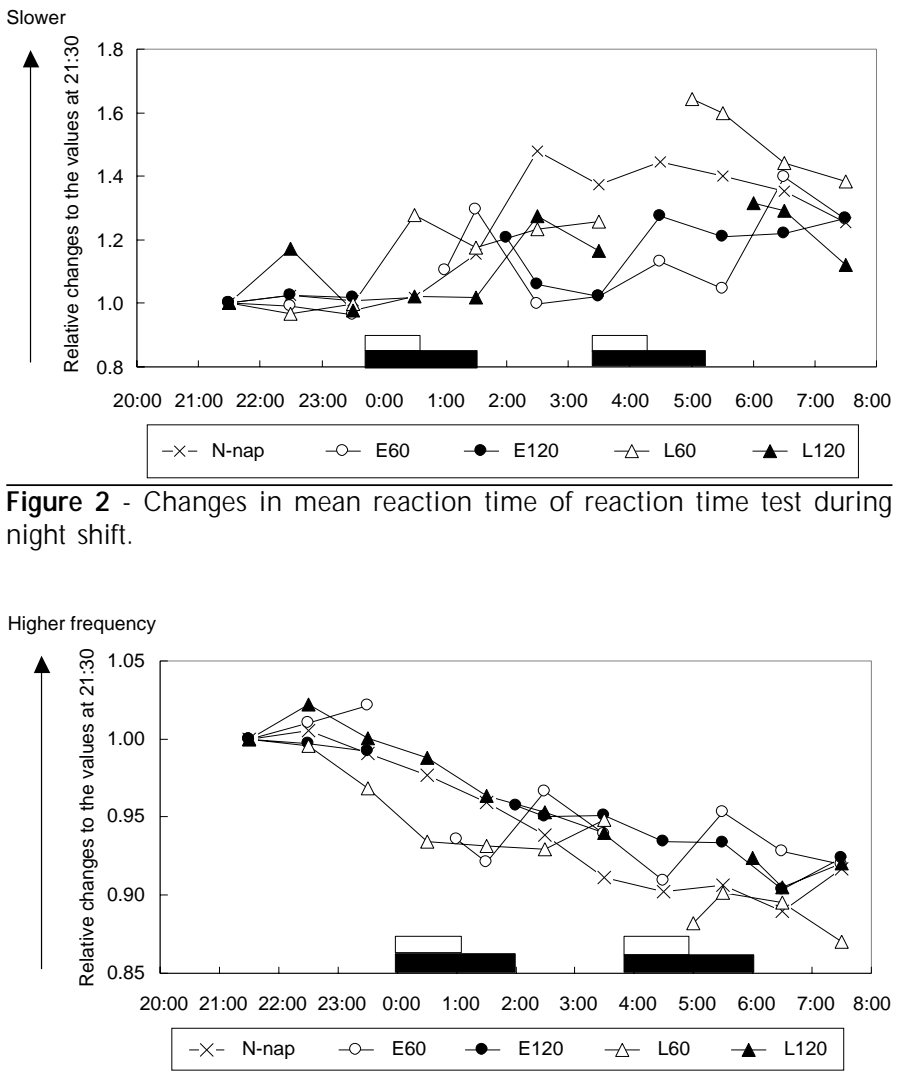

Figure 3 - Changes in CFF values during night shift.

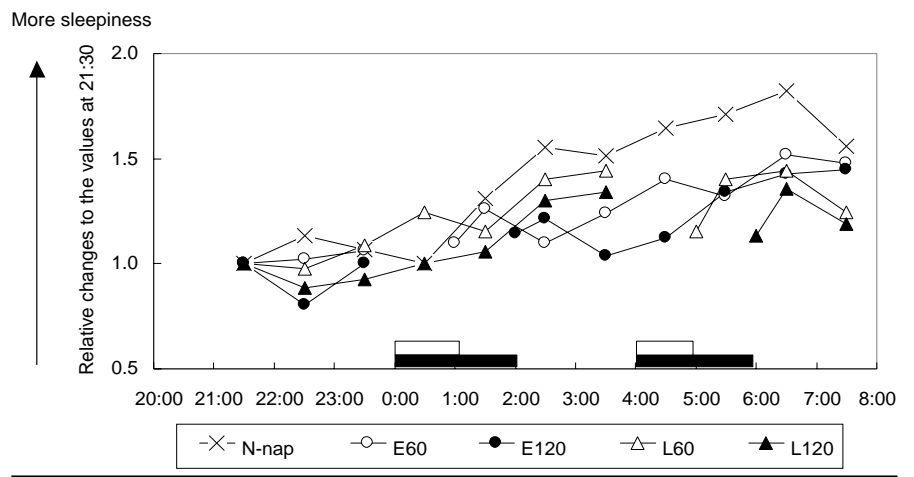

Figure 4 - Changes in subjective feeling of sleepiness during night shift

min naps in the first half of the night shift tended to be improved for a while after awakening. Task performances following the later two naps showed no clear improvements after awakening regardless of the superior sleep quality achieved. On the contrary, performance deteriorated after awakening for the later 60-min nap. Lubin et $\mathrm{al}^{7}$ reported that performance decreased immediately after taking a nap and the effect of this "sleep inertia" continued for 5-15 minutes after waking. Previous studies have indicated that both duration and intensity vary. Dinges et $\mathrm{al}^{3}$ reported that deeper sleep just before awakening leads to more severe sleep inertia. Naitoh ${ }^{9}$ suggested that sleep inertia might be more severe around the cir- cadian nadir than at other times of the day.

In the present study the relations between degrees of sleep inertia and sleep stage upon awakening were not consistent between participants. In addition, the slower reaction time continued until the end of the night shift. Sallinen et $\mathrm{al}^{14}$ examined the effects of 50min and 30-min naps on three-shift workers with timing similar to that in our study. However, their results indicated no serious sleep inertia and no difference between earlier and later naps. Our findings were not consistent with previous studies regarding the severity and duration of sleep inertia. We have identified no convincing explanations for this difference so far. It might be due to slight differences in nap length and timing or different experimental conditions. In VT, the reaction times between the No-nap condition and L120 were already different at the beginning of the night shift. In this study, the participants were informed which nap condition they had to perform at beginning the experiments. It was presumed that some psychological factors partly caused the differences between the Nonap condition and L120.

Subjective feelings of sleepiness in this study were not clearly reduced by the naps. Saito \& Sasaki ${ }^{13}$ reported that subjective fatigue was clearly decreased by both a 1- and 2-hour nap. Our results were not consistent with their study. The score for local pain or dullness in L60 and L120 tended to decrease after a nap regardless of significant sleep inertia. Further studies with larger sample sizes are necessary to resolve such discrepancies.

In summary, naps in the second half of the night shift were superior to earlier naps in terms of sleep quality. However performance declined after a 1-hour nap taken later in the night shift due to sleep inertia. It was suggested from this study a short (60 minute) nap must be carefully timed to gain optimum benefit. The number of participants in this study was low $(n=6)$, producing low statistical power. Therefore, further investigations using larger sample sizes are necessary.

\section{ACKN O WLED GEMENT}

The authors express their appreciation to the Tokyo Electric Power Company for leasing the electroencephalograph and performance test battery for this study. 


\section{REFEREN CES}

1. Akerstedt T. Psychological and psychophysiological effects of shift work. Scand J Work Environ Health 1990;16:67-73.

2. Baddeley AD. A 3-min reasoning task based on grammatical transformation. Psychonom Sci 1968:10:341-2.

3. Dinges DF, Orne MT, Orne EC. Assessing performance upon abrupt awakening from naps during quasi-continuous operations. Behav Res Methods Instrum Comput 1985;17:37-45.

4. Dinges DF. An overview of sleepiness and accidents. J Sleep Res 1995;4:4-14.

5. Gillberg $M$. The effects of two alternative timings of a one-hour nap on early morning performance. Biol Psychol 1984;19:45-54.

6. Kogi K. Sleep problems in night and shiftwork. J Hum Ergol (Tokyo) 1982;11:217-31.

7. Lubin A, Hord D, Tracy M, Johnson LC. Effects of exercise, bedrest and napping on performance decrement during 40 hours. Psychophysiology $1987 ; 13: 334-9$

8. Matsumoto K. Effects of nighttime naps on body temperature changes sleep patterns, and self-evaluation of sleep. J Hum Ergol (Tokyo) 1981;10:173-84.
9. Naitoh P, Angus RG. Napping and human functioning during prolonged work. In: Dinges DF,Broughton RJ, editors. Sleep and alertness: chronobiological, behavioral and medical aspects of napping. New York: Raven Press; 1989. p. 221-46.

10. O htomo N, Tanaka $\mathrm{Y}$. N ew method of time series analysis and 'MemCalc'. In: Saito K, editor. A recent advance in time-series analysis by maximum entropy method. Hokkaido: Hokkaido U niversity Press; 1994. p. 11-29.

11. Purnell MT, Feyer AM, Herbison P. The impact of a nap opportunity during the night shift on the performance and alertness of 12 -h shift workers. $J$ Sleep Res 2002;11:219-27.

12. Rechtschaffen A, Kales A. A manual of standardization terminology, techniques and scoring systems for sleep stages of human subjects. Washington (DC): US Government Printing Office; 1968.

13. Saito $Y$, Sasaki T. The effect of length of a nocturnal nap on fatigue feeling during subsequent early morning hours. J Sci Labour 1996;72:15-23.

14. Sallinen $M$, Harma $M$, Akerstedt $T$, Rosa R, Liiqvist $O$. Promoting alertness with a short nap during a night shift. J Sleep Res 1998;7:240-7.

15. Tachi N, Itani T, Sakai K, Kondo $Y$, Seo A, Sasaki T et al. Validity of a newly developed questionnaire for evaluating work-related fatigue feeling. $27^{\text {th }}$ International Congress on O ccupational Health. 